\title{
The Practice of Hospital Dentistry in a Reference Hospital in Brazil
}

\section{Halime Adel Saleh ${ }^{1}$, Mariah Luz Lisboa ${ }^{2}$, Carolina S Flausino ${ }^{3}$, Sarah FM Pilati², Joanita Angela Gonzaga Del Moral ${ }^{4}$, Etiene de Andrade Munhoz ${ }^{5}$, and Alessandra Rodrigues de Camargo ${ }^{5 *}$}

\author{
${ }^{1}$ Undergraduate Student, Federal University of Santa Catarina, Florianópolis-SC, Brasil \\ ${ }^{2}$ Doctor Student, Federal University of Santa Catarina, Florianópolis-SC, Brasil \\ ${ }^{3}$ Master Student, Federal University of Santa Catarina, Florianópolis-SC, Brasil \\ ${ }^{4}$ Department of Medicine, Polydoro Ernani University Hospital of São Thiago, Federal University of Santa Catarina, Florianópolis-SC, Brasil \\ ${ }^{5}$ Department of Dentistry, Health Sciences Center, Federal University of Santa Catarina, Florianópolis-SC, Brasil
}

*Corresponding author: Alessandra Rodrigues de Camargo, Professor, Department of Dentistry, Health Sciences Center, Federal University of Santa Catarina, Florianópolis-SC, Brasil, Tel: 55483721-2094; E-mail: alessandrarcamargo@gmail.com

Received: 09 Sep, 2019 | Accepted: 01 Oct, 2019 | Published: 07 Oct, 2019

Citation: Saleh HA, Lisboa ML, Flausino CS, Pilati SFM, Moral JAGD, et al. (2019) The Practice of Hospital Dentistry in a Reference Hospital in Brazil. Int J Dent Oral Health 5(6): dx.doi.org/10.16966/2378-7090.304

Copyright: (C) 2019 Saleh HA, et al. This is an open-access article distributed under the terms of the Creative Commons Attribution License, which permits unrestricted use, distribution, and reproduction in any medium, provided the original author and source are credited.

\author{
Abstract \\ Objective: To compare the oral health status in two groups of oncohematological patients in a reference hospital in the south of Brazil.
}

Methods: A retrospective cohort analytical study based on medical records review of adult's in patients with onco-hematological diseases followedup from April/2013 to April/2015. For data inclusion criteria it was considered in patients with onco-hematological disease, considering the death cases. Exclusion data criteria were absence or questionable information on medical records, inaccessibility of medical records as well inconsistency between information described by nursing team, medical team, dental team and others. The inpatients were divided into two groups: (A) without dental supportive care-considering inpatients with onco-hematological diseases who received dental assistance only in emergency cases; (B) with dental supportive care-considering inpatients with onco-hematological disease who received dental assistance regularly during hospitalization. The data collection consisted of gender, onco-hematological malignancies, presence of oral complications related to chemotherapy, and dental emergency during the hospitalization period. A descriptive analysis, Qui and Fischer Tests were performed.

Results: A total of 114 inpatients were enrolled, 55 (48.2\%) on Group A and 59 (51.7\%) on Group B. There was a male predominance in the sample $(n=65)$. The Acute Myeloid Leukemia (17.5\%) and Non-Hodgkin's Lymphoma (13.1\%) were the major oncohematological malignancies diagnosed. Oral candidiasis was the major complication related to chemotherapy treatment in both groups. There was an association between regular dental supportive care and the diagnosis of oral complications due chemotherapy treatment $(p<0.001)$.

Conclusions: The presence of the dentists in the hospital environment has led to enhanced diagnostic accuracy in our sample, contributing to the improvement of the quality of life of inpatients. Further researches on this nature are important to augment performance of dental practice in the hospital setting.

Keywords: Dentistry; Hospital; Oncohematological disease

\section{Introduction}

Dental care at the hospital setting started to become a reality among some Brazilian institutions and universities. There are no documents describing the beginning of clinical practice in hospital, however, seems that it started at half of $20^{\text {th }}$ century, as a consequence of the need to provide global attention in health care for inpatients, including the participation of the dentist in the hospital team [1].

In 2013, the project No. $2776 / 08$ of the Chamber of Deputies was approved in the Legislative House which establishes the presence of the dentist in Intensive Care Units (ICU), both in the public and private hospitals [2]. In 2019, the project was approved by the
Senate; however it was rejected by presidential sanction, and is still in discussion. Another project from 2015, No. 866/2015 [3], is still in process for approval in the Chamber of Deputies, which provides the installation of a sector for dental services in public hospitals. The most recent project from 2019 No. 883/2019 [4], that is also still in process in the Chamber of Deputies, preconize the presence of dental professionals in ICUs in addition to hospital units where the patients stays for a long period of time.

In 2015 the Brazilian Federal Council of Dentistry found the recognition of the dental care in hospital environment as a habilitation modality for dentists, with the resolution 162 [5]. 
The presence of the dentist in the hospital setting collaborates to medical diagnostics; also contributes to the multiprofessional actuation on the control and evolution of diseases. In addition, the participation of a dental surgeon aims to improve patient's general health condition due to the fact that inpatients have medical attention focused on the disease that caused their hospitalization, neglecting oral hygiene. However, it is already proved that poor oral health can result in infections and systemic complications, reinforcing the need of a dental surgeon for the treatment of these and other oral complications that appear during oncological treatment [6]. Many inpatients in ICU present side effects and several conditions, including: hyposalivation associated with medicaments, chewing and swallowing discomfort due to antineoplastic treatments, presence of oral lesions provoked by systemic diseases, and difficulty in oral hygiene during hospitalization. Together, these factors may justify the expertise of the dentist actuation [7].

Considering the challenge of improving in patients assistance and the influence of the dentist to provide health care, this study aimed to compare the oral health in two groups of onco-hematological patients in a reference hospital in the south of Brazil.

\section{Materials and Methods}

A retrospective cohort analytical study based on medical records review of adult's in patients with onco-hematological diseases followedup from April/2013 to April/2015 was conducted at Universitary Hospital of Federal University of Santa Catarina. The research was approved by the Ethics Committee in Human Research of the Federal University of Santa Catarina under the protocol 1.340.271.

The inclusion criteria considered for the data research in the two study groups was: in patients with onco-hematological considering the death cases. Exclusion data criteria were absence or questionable information on medical records, inaccessibility of medical records as well inconsistency between information described by nursing team, medical team, dental team and others.

For the study, inpatients were divided into two groups: (A) without dental supportive care-considering in patients with oncohematological diseases who received dental assistance only in emergency cases and were hospitalized from April $8^{\text {th }}$ of 2013 until April $8^{\text {th }}$ of 2014; (B) with dental supportive care-considering inpatients with onco-hematological disease who received dental assistance regularly during hospitalization from April $9^{\text {th }}$ of 2014 to April $8^{\text {th }}$ of 2015, period when the dental surgeon hospital team started the project to assist onco-hematological inpatients regularly. Participate of these project four professors of Dentistry College that can achieve specialty's as stomatology, patients with special needs, dentistics, endodontics and pediatric dentistry. Also, a dental surgeon from hospital staff and two residents of the multiprofessional residence in health.

The information collected were based on the criteria proposed by Sonis ST, et al. [8] and Vera-Llonch M, et al. [9], which includes: gender, onco-hematological malignancies, previous and current use of medication, parenteral nutrition, days of hospitalization, presence of oral complications related to chemotherapy, dental emergency during the hospitalization period.

A descriptive analysis based on frequency tables with Chi-Square Test and Fischer Tests were performed to verify the statistical association between the variables of interest. The program BioEstat ${ }^{\circ}$ was used.

Relative Risk Estimates (RE), with a 95\% confidence interval (95\% $\mathrm{CI})$, were calculated to assess the association between the outcome (maximum degree) and explanatory variables of interest. $\mathrm{P}$ values less than 0.05 were considered as statistically significant.

\section{Results}

A total of 114 in patients were enrolled, 55 (48.2\%) on Group A and 59 (51.7\% on Group B. Medical records were searched, but 37 were excluded due to loss of information or lack of access.

Globally there was a male predominance $(n=65)$. The Acute Myeloid Leukemia (17,5\%) and Non-Hodgkin's Lymphoma (13,1\%) were the major oncohematological malignancies diagnosed. Socidemographic and the distribtution of oncohematological malignancies are described in table 1.

Comparing the supportive care provided by dental staff, only 2 in patients of Group A required an emergency assistance (3.6\%); on the other hand, all inpatients in Group B (100\%) received regular appointments by the dental hospital team.

Oral candidiasis was the major complication related to chemotherapy treatment in both groups ( 2 in Group A vs 10 in Group B). There was an association between regular dental supportive care and the diagnosis of oral complications due chemotherapy treatment $(p<0.001)$. The evaluation of frequencies of parenteral nutrition and prescriptions of medications, respectively, showed no differences between the groups. Table 2 summarizes the oral complications noticed.

Table 1: Socidemographic and the distribtution of oncohematological malignancies.

\begin{tabular}{|l|c|c|c|}
\hline \multicolumn{1}{|c|}{ Variable } & Group A & Group B & Total Group \\
\hline Gender & 55 & 59 & 114 \\
\hline Male & 32 & 33 & 65 \\
\hline Female & 23 & 26 & 49 \\
\hline Oncohematological malignancies \\
\hline AML & 12 & 8 & 20 \\
\hline ALL & 3 & 3 & 6 \\
\hline CLL & 1 & 3 & 4 \\
\hline NHL & 10 & 5 & 15 \\
\hline HL & 2 & 2 & 4 \\
\hline MM & 4 & 5 & 9 \\
\hline Others & 23 & 33 & 56 \\
\hline
\end{tabular}

AML: Acute Myeloid Leukemia; ALL: Acute Lymphoid Leukemia; CLL: Chronic Lymphoid Leukemia; NHL: Non-Hodking Lymphoma; HL: Hodking Lymphoma; MM: Multiple Myeloma

Table 2: Oral complications related to chemotherapy.

\begin{tabular}{|l|c|c|c|c|}
\hline \multicolumn{1}{|c|}{ Variable } & Group A & Group B & p Value & Total Group \\
\hline Oral complication & 4 & 43 & -- & 47 \\
\hline Mucositis & 0 & 6 & $\mathrm{p}=0.044^{* * *}$ & 6 \\
\hline Oral Candidiasis & 2 & 10 & $\mathrm{p}<0,001^{* *}$ & 12 \\
\hline Hyposalivation & 0 & 4 & $\mathrm{p}<0,001^{* *}$ & 4 \\
\hline Leukoplakia & 0 & 1 & $\mathrm{p}=0.97^{* * *}$ & 1 \\
\hline Dental Caries & 0 & 5 & $\mathrm{p}=0.08^{* * *}$ & 5 \\
\hline Tumor & 0 & 2 & $\mathrm{p}=0.50^{* * *}$ & 2 \\
\hline Others* & 2 & 24 & -- & 26 \\
\hline
\end{tabular}

*Others: Actinic cheilitis, gingivits, traumatic ulcer, dental mobility, pericoronitis, dental calculus, friction, abrasion, erosion, lip herpes and others

**Chi-Square Test

$* * *$ Fischer Test 


\section{Discussion}

In Brazil, the inclusion of hospital dentistry in association to a multiprofissional team has gained importance for supportive care of oncologic inpatients. Some anti-neoplastic therapies as chemotherapy and radiotherapy are associated to significant collateral effects with repercussion in the oral cavity, such as: oral mucositis, hyposalivation and oral opportunist infections [10].

According to Albuquerque RA, et al. [11], these alterations may cause pain and discomfort, feeding difficulty and poor oral hygiene maintenance. Souza IS, et al. [12] reinforces that poor oral hygiene can lead to oral complications which can lead a systemic disorder in inpatients, due to accumulation of microorganisms. In relation to the oral cavity, the dentist acting has a crucial participation on prevention and treatment of these complications Hong CHL, et al. [10].

The main objective of the present study was to analyze the oral health $t$ in the onco-hematological inpatients in a reference hospital in the south of Brazil. Our results support that the presence of dentist in the hospital environment brings benefits to the inpatients, improving the diagnostic and treatment of oral complications related to chemotherapy during hospital stay, and patient's general condition, preventing infections and systemic complications.

The results of our study shows that onco-hematological diseases were more prevalent in men when compared to women, this data can be explained by the National Institute of Cancer Estimative made by Brasil [13] where it is demonstrated that onco-hematological diseases ranks ninth most common cancer in men and in women ranks tenth. About the type of hematological cancer, the Brasil [14] in National Institute of Cancer brings that Acute Myeloid Leukemia represents $80 \%$ of onco-hematological diseases in adults, what correspond to our findings where, besides other types of onco-hematological diseases, the Acute Myeloid Leukemia is the most prevalent among them. Institution reports that the Non-Hodgkin Lymphoma, described by Brasil [15], also has a high frequency in young adults, what explains the second result demonstrated by table 1 .

Related to Oral Complications, in both groups the Oral Candidiasis was the major complication noticed followed by Oral Mucositis in Group B. In our sample, the appearance of chemotherapy-related oral complications occurs regardless of the prescription of a prophylactic protocol composed of antibiotics, antifungals and antivirals, prescribed by the medical team. These results are similar to those presented by Watters AL, et al. [16], where a high prevalence of Oral Mucositis, Xerostomia and Candidiasis was correlated to use of Cetuximab due to radiotherapy in patients during therapy.

It is known that the anti-neoplastic treatment compromises the immunologic system and predisposes the patients to opportunist infections, as stated Zadik Y, et al. [6]. In addition, the accuracy of diagnosis by the dentist's team in a hospital environment could improve the comfort of inpatients during hospitalization stay [11]. Although incipient, our research shows the benefits of a referral system of communication between the dental and the medical support team that was implemented in our hospital in April/2014, for oncohematological patients.

The lack of oral hygiene instructions was an important task observed in Group A. Some strategies were implemented in Group B: all inpatients received instructions for oral hygiene, reinforcing the importance of oral health. Unfortunately, oral hygiene kits are not distributed by the hospital and the nursing team it is not qualified or trained to perform oral hygiene and proper oral care instructions.
Measures to optimize these approaches were initiated at the ICU as model for other areas of hospital environment.

Studies by Potting CM, et al. [17], Paspatravou E, et al. [18] and Eilers J, et al. [19] corroborate with our results and affirm that the oral health must be considered a determinant factor to improve a bigger comfort for the oncologic inpatient and should receive special attention regarding their care. The inpatient that presents a good oral health feels more comfortable, can eat better avoiding parenteral nutrition and prolonged hospital stays. Also, current studies as the presented by Cheng KK, et al. [20] and Eilers J, et al. [19] show that maintaining good oral hygiene throughout the chemotherapy cycle may decrease the degree of oral mucositis in inpatients. Given this data, we consider that the specialized oral hygiene guidance promoted by the Hospital Dentistry team of UH/UFSC should be qualified as a gain for inpatients, considering the statistical significance of this data.

All inpatients included in Group B had access to dental treatment before hospitalization stay by dentist's staff, and the mainly dental problem notice before the hospital stay was caries and periodontal disease. This conduct justifies the low incidence of dental caries diagnose in Group B.

During the hospital stay, the oral monitoring supportive care may shorten the hospitalization time at the same time which reduces costs and increase a good general health reducing morbidity (oral infections rates) and mortality. These data were not verified in our results, which can be considered as a possible limitation.

The register of the history of the inpatients in the medical records consists of an important tool for treatment control and patient's follow-up [21]. Patient's data in the hospital are placed in paper records, which makes it possible to follow-up patient health status for all teams, including medical, dental, nursing, nutrition and others. After any procedure data are updated by the professional and archived. Unfortunately, in our sample, 37 inpatients were discharged due to loss of information in medical records or lack of access. In some of records was difficult to understand the patient's evolution; in others, the illegible writing and missing pages compromised the collection of data.

Previous reports observed several errors in a study conducted to analyze medical records, such as incomplete information's, spelling errors and use of non-standard acronyms as well. The authors concluded that poor and inadequate evolution in medical records compromises patient care and quality of care in the institution [21].

\section{Conclusion}

The presence of the dentists in the hospital environment has led to enhanced diagnostic accuracy in our sample, contributing to detection of opportunistic diseases and frequent oral complications in onco-hematological patients providing a better overall health for inpatients. Further researches on this nature are important to augment performance of dental practice in the hospital setting.

\section{References}

1. Santos PSS, Soares Jr LAV (2012) Medicina bucal: a prática na odontologia hospitalar.

2. Mulim N (2013) Projeto de Lei N.²776-B, de 2008. Câmara Dos Deputados.

3. Heringer $M$, Neto A (2015) Dispõe sobre a instalação de setor destinado a prestação de serviços de odontologia nos Hospitais Públicos e dá outras providências. PL 886/2015 Projeto de Lei. 
4. Alguz R (2019) Declara de utilidade pública a Irmandade da Santa Casa de Angatuba, com sede naquele Município. Projeto de Lei $\mathrm{n}^{\circ}$ $883 / 2019$

5. Odontologia Hospitalar é reconhecida como habilitação pelo CFO (2015) O Conselho Federal de Odontologia, na resolução no 162.

6. Zadik Y, Arany PR, Fregnani ER, Bossi P, Antunes HS, et al. (2019) Systematic review of photobiomodulation for the management of oral mucositis in cancer patients and clinical practice guidelines. Support Care Cancer 27: 3969-3983.

7. Lemaster M (2013) Pilot program provides oral health services to long term care facility residents through service learning and community partnership. J Am Med Dir Assoc 14: 363-366.

8. Sonis ST, Oster G, Fuchs H, Bellm L, Bradford WZ, et al. (2001) Oral Mucositis and the Clinical and Economic Outcomes of Hematopoietic Stem-Cell Transplantation. J Clin Oncol 19: 2201-2205.

9. Vera-Llonch M, Oster G, Ford CM, Lu J, Sonis S (2007) Oral mucositis and outcomes of allogeneic hematopoietic stem-cell transplantation in patients with hematologic malignancies. Support Care Cancer 15: 491-496.

10. Hong CHL, Gueiros LA, Fulton JS, Cheng KKF, Kandwal A, et al. (2019) Systematic review of basic oral care for the management of oral mucositis in cancer patients and clinical practice guidelines. Support Care Cancer 27: 3949-3967.

11. Albuquerque RA, Morais VLL, Sobral APV (2007) Protocolo de atendimento odontológico a pacientes oncológicos pediátricosrevisão da literatura. Rev Odontol UNESP 36: 275-280.

12. Souza IS, Santaella NG, Santos PSS (2017) The practice of hospital dentistry in Brazil: an integrative literature review. Rev Bras Odontol 74: 232-239.
13. ESTIMATIVA (2014) Ministério da Saúde Instituto Nacional de Câncer José Alencar Gomes da Silva.

14. Condutas do Inca (2002) Leucemia Mielóide Aguda em Adultos. Revista Brasileira de Cancerologia 48: 313-315.

15. Instituto Nacional de Câncer (2018) Linfoma não Hodgkin-versão para Profissionais de Saúde.

16. Watters AL, Epstein JB, Agulnik M (2011) Oral complications of targeted cancer therapies: a narrative literature review. Oral Oncol 47: 441-448.

17. Potting $\mathrm{CM}$, Mank A, Blijlevens NM, Donnelly JP, van Achterberg $T$ (2008) Providing oral care in haematological oncology patients: nurses' knowledge and skills. Eur J Oncol Nurs 12: 291-298.

18. Papastravou E, Charalambous A, Vryonides S, Eleftheriou C, Merkouris A (2016) To what extent are patients' needs met on oncology units? The phenomenon of care rationing. Eur J Oncol Nurs 21: 48-56.

19. Eleilers J, Million R (2007) Prevention and management of oral mucositis in patients with cancer. Semin Oncol Nurs 23: 201-212.

20. Cheng KK, Molassiotis A, Chang AM, Wai WC, Cheung SS (2001) Evaluation of an oral care protocol intervion in the prevention of chemotherapy-induced oral mucositis in paediatric cancer patients. Eur J Cancer 37: 2056-2063.

21. Setz VG, D'Innocenzo M (2009) Avaliação da qualidade dos registros de enfermagem no prontuário por meio da auditoria. Acta Paul Enferm 22: 313-317. 